Provided for non-commercial research and education use. Not for reproduction, distribution or commercial use.

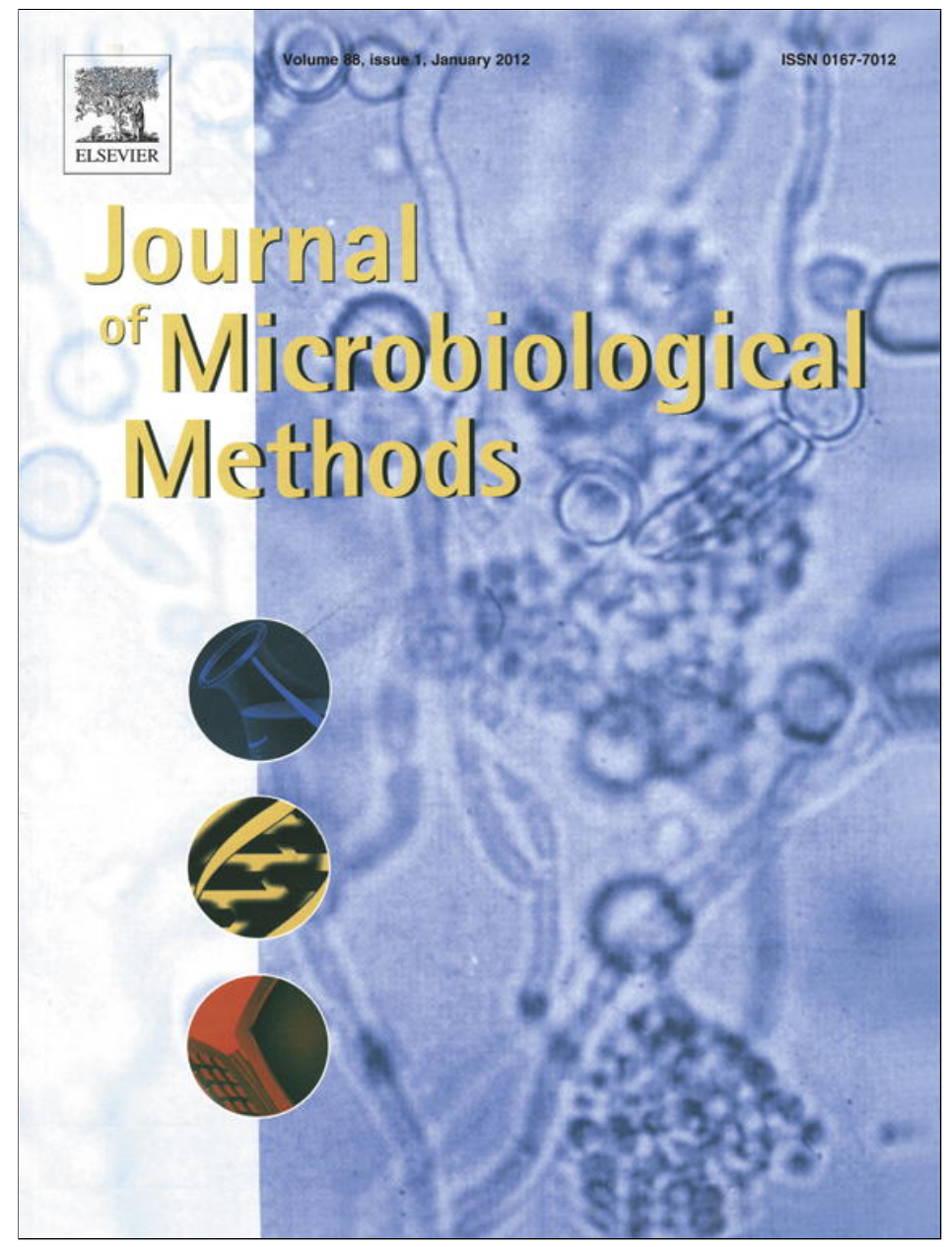

This article appeared in a journal published by Elsevier. The attached copy is furnished to the author for internal non-commercial research and education use, including for instruction at the authors institution and sharing with colleagues.

Other uses, including reproduction and distribution, or selling or licensing copies, or posting to personal, institutional or third party websites are prohibited.

In most cases authors are permitted to post their version of the article (e.g. in Word or Tex form) to their personal website or institutional repository. Authors requiring further information regarding Elsevier's archiving and manuscript policies are encouraged to visit:

http://www.elsevier.com/copyright 


\title{
A polyphasic approach for the characterization of endophytic Alternaria strains isolated from grapevines
}

\author{
Rachele Polizzotto a , Birgitte Andersen ${ }^{\text {b }}$, Marta Martini ${ }^{a}$, Simone Grisan ${ }^{a}$, Gemma Assante ${ }^{\mathrm{c}}$, Rita Musetti ${ }^{\mathrm{a}, *}$ \\ a Department of Agricultural and Environmental Sciences, University of Udine, via delle Scienze208, I-33100 Udine, Italy \\ ${ }^{\mathrm{b}}$ Department of Systems Biology, Technical University of Denmark, 2800 Kgs. Lyngby, Søltofts Plads, Building 221, DK-2800 Kgs. Lyngby, Denmark \\ c Dipartimento di Produzione Vegetale, Sezione di Patologia Vegetale, Università di Milano, via Celoria 2, I-20133 Milano, Italy
}

\section{A R T I C L E I N F O}

\section{Article history:}

Received 28 September 2011

Received in revised form 10 November 2011

Accepted 12 November 2011

Available online 23 November 2011

\section{Keywords:}

Morphology

RAPD

Chemotaxonomy

Metabolite profiling

\begin{abstract}
A B S T R A C T
A polyphasic approach was set up and applied to characterize 20 fungal endophytes belonging to the genus Alternaria, recovered from grapevine in different Italian regions.

Morphological, microscopical, molecular and chemical investigations were performed and the obtained results were combined in a pooled cluster analysis. Following morphological analyses, all strains were grouped according to their three-dimensional sporulation pattern on PCA and to the colony characteristics on different substrates. After DNA extraction, all strains were analyzed by RAPD-PCR and the resulting profiles were subjected to cluster analysis. The metabolites extracted from the 20 Alternaria endophytes were analyzed by a HPLC and the resulting metabolite profiles were subjected to multivariate statistic analyses. In comparison with reference 'small-spored' Alternaria species, the 20 strains were segregated into two morphological groups: one belonging to the $A$. arborescens species-group and a second to the $A$. tenuissima species-group. RAPD analysis also showed that grapevine endophytes belonged to either the A. arborescens or the A. tenuissima species-group and that they were molecularly distinct from strains belonging to $A$. alternata. Chemotaxonomy gave the same grouping: the grapevine endophytic strains belong to A. arborescens or $A$. tenuissima speciesgroups producing known metabolites typical of these species-groups. Interestingly, the 20 grapevine endophytes were able to produce also a number of unknown metabolites, whose characterization could be useful for a more precise segregation of the two species-groups.

The results show how complementary morphological, molecular and chemical data can clarify relationships among endophyte species-groups of low morphological divergence.
\end{abstract}

(c) 2011 Elsevier B.V. All rights reserved.

\section{Introduction}

Genus Alternaria Ness is ubiquitous, including species found worldwide in association with a large variety of substrates. Many species are saprophytes, animal/plant pathogens or postharvest pathogens. As a genus, Alternaria encompasses considerable morphological diversity and there have been a number of attempts to organize taxa into subgeneric groupings based on shared morphological characters. Above all, small-spored Alternaria species are a taxonomically challenging group of fungi with few morphological or molecular characters that allow unambiguous discrimination among taxa (Andrew et al., 2009).

A precise and correct identification of these species is necessary, not only because of our desire to classify and control, but also because the species name embodies a set of characters (e.g., growth preference, host interaction and metabolite production) that enables us to predict its behavior.

\footnotetext{
* Corresponding author.

E-mail address: Rita.Musetti@uniud.it (R. Musetti).
}

In spite of the numerous studies on different Alternaria spp., few reports deal with the characterization of the endophytic strains (Guo et al., 2004).

Studies have shown that small-spored Alternaria species often dominate among endophytic fungi isolated from leaves and other tissue parts of various plant groups (Dugan and Lupien, 2002; Dugan et al., 2002; Su et al., 2010). Depending on the plant group, different species-groups or complexes of Alternaria have been isolated. In grasses A. infectoria dominated (Dugan and Lupien, 2002), while $A$. alternata complex was the most frequent group found in grapevine (Mostert et al., 2000; Grisan et al., 2011).

In the case of the grapevine, it has been reported that some categories of endophytes may potentially provide control of important diseases (Kortekamp, 1997; Musetti et al., 2006; Bulgari et al., 2011); others are successfully used as biocontrol agents against postharvest pathogens (e.g., Botrytis cinerea and Penicillium expansum) (Schena et al., 1999). In particular, fungi belonging to the genus Alternaria, have been demonstrated to inhibit Plasmopara viticola sporulation in grapevine leaves in moisture chambers as well as in plants maintained in the greenhouse, producing secondary metabolites 
belonging to the class of Diketopiperazines (Musetti et al., 2007; Polizzotto et al., 2009).

Therefore, the correct classification of endophytic Alternaria acquires importance also under a practical point of view.

Gene sequence analyses of ITS and other household genes can distinguish $A$. infectoria from other small-spored Alternaria species (Pryor and Bigelow, 2003), but are not able to distinguish between $A$. alternata, the $A$. arborescens and the $A$. tenuissima species-groups (Hong et al., 2005). Characterization of Alternaria species based on morphological (Andersen et al., 2005) and molecular analyses (e.g., RAPD-PCR and PCR-RFLP) (Roberts et al., 2000; Pryor and Michailides, 2002; Hong et al., 2005) are important for a correct identification, but may not be enough to differentiate pathogenic strains from endophytic ones. It is known that many endophytes are able to produce secondary metabolites with biological activities and that they can contribute to their classification (Azevedo et al., 2000; Shultz et al., 2002). A classification based on the profile of secondary metabolites is very important as it reflects the major signals of importance for interactions with the environment. Furthermore, in itself the secondary metabolism is a powerful feature for fungal characterization and offers the opportunity to classify and identify also endophyte microorganisms presenting often difficulties in the differentiation of reproducing structures in laboratory conditions (Frisvad et al., 2008).

Segregation, therefore, must be based on other types of molecular analyses (e.g., RAMS, RAPD-PCR and PCR-RFLP) (Roberts et al., 2000; Pryor and Michailides, 2002; Guo et al., 2004; Hong et al., 2006) together with chemical and morphological methods suited for Alternaria (Andersen et al., 2002).

A polyphasic approach including morphology and molecular analyses and metabolite profiling should give a good basis to characterizing endophytes belonging to the genus Alternaria.

The aim of this work was to set up an integrated approach for the characterization of Alternaria endophytic strains isolated from different origins, using morphological, molecular and chemical methods in order to facilitate the understanding of endophyte properties and the interactions with the host plants. Another aim was to determine if endophytic Alternaria strains isolated from grapevine belong to known taxa or constitute new undescribed species.

\section{Materials and methods}

\subsection{Strains used in this study}

Thirty-two Alternaria strains were used in this study: twenty endophytic fungal strains belonging to the genus Alternaria that had been isolated from grapevine shoots in a previous study (Musetti et al., 2006; Martini et al., 2009) and twelve representative strains belonging to four 'small-spored' Alternaria species-groups. Identity and origin of all strains are given in Table 1 . A temporary working collection of the strains was made from agar blocks with conidia from potato carrot agar (PCA) (Simmons, 1992) placed in cryo tubes and kept at $5{ }^{\circ} \mathrm{C}$. All strains were maintained and stored in sterile water at about $5{ }^{\circ} \mathrm{C}$ and in glycerol $20 \%$ at $-20^{\circ} \mathrm{C}$ and are available from the authors' private collections at Department of Agricultural and Environmental Sciences (DISA), University of Udine, Italy and from the IBT collection at the Department of Systems Biology, DTU, Denmark.

\subsection{Growth media and growth conditions}

To ensure purity and generate inoculum, all 32 strains were inoculated on PCA and grown under standardized conditions (Andersen et al., 2005). The unsealed 9-cm plates were incubated in one layer for 7 days at $23{ }^{\circ} \mathrm{C}$ under an alternating light/dark cycle consisting of $8 \mathrm{~h}$ of cool-white fluorescent daylight and $16 \mathrm{~h}$ darkness. Conidia from PCA cultures of each strain were transferred to the following
Table 1

Alternaria strains used in the study.

\begin{tabular}{|c|c|c|c|c|}
\hline $\begin{array}{l}\text { Isolate } \\
\text { code }^{\mathrm{a}}\end{array}$ & $\begin{array}{l}\text { Species/species } \\
\text { group }^{\mathrm{b}}\end{array}$ & Type & Host/substratum & Origin \\
\hline BA961 & A. arborescens sp-grp & Saprophyte & Tomato fruit & - \\
\hline BA925 & A. tenuissima sp-grp & - & Air & - \\
\hline BA924c & A. alternata & Saprophyte & Banana & - \\
\hline BA923 ${ }^{\mathrm{C}}$ & A. alternata & Saprophyte & Datura & - \\
\hline BA922 ${ }^{\mathrm{C}}$ & A. alternata & Saprophyte & Peanut & - \\
\hline BA879 ${ }^{\mathrm{C}}$ & A. tenuissima sp-grp & Saprophyte & Moldy grape berry & Denmark \\
\hline BA853 ${ }^{\mathrm{C}}$ & A. tenuissima sp-grp & Saprophyte & Moldy tomato fruit & Denmark \\
\hline BA1422 & A. arborescens sp-grp & - & Saltmarch & Slovenia \\
\hline BA1382 & A. arborescens sp-grp & - & Insect gall, Nerium & Spain \\
\hline BA $1343^{c}$ & A. arborescens sp-grp & Saprophyte & Grain, barley & Denmark \\
\hline BA1208 ${ }^{c}$ & A. incomplexa & - & Mud & - \\
\hline BA1240 ${ }^{\mathrm{d}}$ & A. infectoria sp-grp & - & - & - \\
\hline A-MELO ${ }^{d}$ & A. arborescens sp-grp & Endophyte & Shoot, grapevine & Italy \\
\hline $\mathrm{M} 44 \mathrm{~B}^{\mathrm{d}}$ & A. tenuissima sp-grp & Endophyte & Shoot, grapevine & Italy \\
\hline $\mathrm{M} 44 \mathrm{C}^{\mathrm{d}}$ & A. tenuissima sp-grp & Endophyte & Shoot, grapevine & Italy \\
\hline $\mathrm{P}^{2} 5 \mathrm{~A}^{\mathrm{d}}$ & A. arborescens sp-grp & Endophyte & Shoot, grapevine & Italy \\
\hline $\mathrm{P} 85 \mathrm{~B}^{\mathrm{d}}$ & A. arborescens sp-grp & Endophyte & Shoot, grapevine & Italy \\
\hline P85Cd & A. arborescens sp-grp & Endophyte & Shoot, grapevine & Italy \\
\hline $\mathrm{P}^{2} 5 \mathrm{D}^{\mathrm{d}}$ & A. arborescens sp-grp & Endophyte & Shoot, grapevine & Italy \\
\hline $\mathrm{R} 42 \mathrm{~A}^{\mathrm{d}}$ & A. arborescens sp-grp & Endophyte & Shoot, grapevine & Italy \\
\hline $\mathrm{R}_{68 \mathrm{~B}^{\mathrm{d}}}$ & A. tenuissima sp-grp & Endophyte & Shoot, grapevine & Italy \\
\hline $\mathrm{R}_{89 A^{\mathrm{d}}}$ & A. arborescens sp-grp & Endophyte & Shoot, grapevine & Italy \\
\hline $\mathrm{R}^{2} \mathrm{~A} 2^{\mathrm{d}}$ & A. tenuissima sp-grp & Endophyte & Shoot, grapevine & Italy \\
\hline $\mathrm{T} 50 \mathrm{C} 1^{\mathrm{d}}$ & A. arborescens sp-grp & Endophyte & Shoot, grapevine & Italy \\
\hline $\mathrm{T} 65 \mathrm{~A}^{\mathrm{d}}$ & A. arborescens sp-grp & Endophyte & Shoot, grapevine & Italy \\
\hline $\mathrm{T}_{65 \mathrm{~B}^{\mathrm{d}}}$ & A. tenuissima sp-grp & Endophyte & Shoot, grapevine & Italy \\
\hline $\mathrm{T} 65 \mathrm{D}^{\mathrm{d}}$ & A. tenuissima sp-grp & Endophyte & Shoot, grapevine & Italy \\
\hline $\mathrm{VP} 12 \mathrm{~A}^{\mathrm{B}} \mathrm{B}^{\mathrm{d}}$ & A. tenuissima sp-grp & Endophyte & Leaf, grapevine & Italy \\
\hline VP12B1A ${ }^{2}$ & A. tenuissima sp-grp & Endophyte & Leaf, grapevine & Italy \\
\hline VP12B2A ${ }^{d}$ & A. tenuissima sp-grp & Endophyte & Leaf, grapevine & Italy \\
\hline VP13B2B $^{d}$ & A. tenuissima sp-grp & Endophyte & Leaf, grapevine & Italy \\
\hline VP13B2B2 $^{d}$ & A. tenuissima sp-grp & Endophyte & Leaf, grapevine & Italy \\
\hline
\end{tabular}

a Identification code as used in Figures.

b Sporulation group according to Simmons and Roberts (1993).

c IBT collection at the Department of System Biology, DTU, Denmark.

d DISA collection, University of Udine, Italy.

five media: PCA, Dichloran Rose Bengal Yeast Extract Sucrose agar [DRYES (Frisvad, 1983)], Potato Dextrose agar (PDA, DIFCO 213400), Malt Extract agar [MEA according to Blakeslee (Samson et al., 2002)] and Dichloran 18\% Glycerol agar [DG18 (Andersen et al., 2009)], as three-point inoculations. All plates, except those with PCA, were staked (six in each) and put in perforated plastic bags and incubated for 14 days in the dark at $25^{\circ} \mathrm{C}$. The PCA plates were incubated unsealed as mentioned above. If sporulation was unsatisfactory, the plates were scarified and incubated longer.

\subsection{Morphological and culture characterisation}

For morphological examination, the PCA cultures were observed after 7 days at $\times 50$ magnification in a stereo-microscope. The sporulation pattern of each culture was examined directly on the plates according to the method of Simmons and Roberts (1993). Further examination was done at $\times 400$ magnification using slides made in lactophenol with tape using a compound microscope. Colony colors on DRYES, PDA, MEA and DG18 were determined according to Kornerup and Wanscher (1978) and pictures were taken of the 7days-old. Twenty micro- and macro-morphological characters (e.g., rough conidial texture, secondary conidiophores originating from apex, green color on DRYES) were recorded as binary data [present (1) or absent (0)] for cluster analysis.

\subsection{Genomic DNA extractions}

Mycelia for DNA extraction was extracted from 7-days-old PDA cultures of Alternaria isolates (Table 1) following the procedure of Lecellier and Silar (1994) modified by Martini et al. (2009). 
The DNA pellet was suspended in $100 \mu \mathrm{l}$ TE buffer and stored at $-20^{\circ} \mathrm{C}$ until further use. DNA concentrations were determined by spectrophotometer (Nanodrop 1000, Spectrophotometer, TermoScientific, Wilmington, USA).

\subsection{RAPD-PCR amplification}

Genomic DNA was amplified using four primers: OPR-02 (Roberts et al., 2000), OPR-12 (Roberts et al., 2000), OPA9 (Cooke et al., 1998) and OPA13 (Cooke et al., 1998). RAPD reactions were carried out in a $25 \mu \mathrm{l} \mathrm{PCR}$ reaction mixture containing $5 \mathrm{ng}$ of DNA, 20 pmol of primer, $150 \mu \mathrm{M}$ of DNTP's, $2 \mu \mathrm{M}$ of $\mathrm{MgCl}_{2}$ and $0.75 \mathrm{U}$ of Go Taq Flexi DNA Polymerase (PROMEGA, USA). Amplification was performed in a thermal cycler (MJ Mini Personal Thermal Cycler, BIORAD) and consisted in an initial denaturation at $94{ }^{\circ} \mathrm{C}$ for 2 min followed by 36 cycles of denaturation at $94^{\circ}$ for $1 \mathrm{~min}$, annealing at $35^{\circ} \mathrm{C}$ for $30 \mathrm{~s}$, extension at $72{ }^{\circ} \mathrm{C}$ for $2 \mathrm{~min}$, and with a final extension at $72{ }^{\circ} \mathrm{C}$ for $8 \mathrm{~min}$. The PCR products $(5 \mu \mathrm{l})$ were resolved by electrophoresis by using $1.5 \%$ agarose gel in $0.5 \times$ TBE buffer $(45 \mathrm{mM}$ Tris-borate, $1 \mathrm{mM}$ EDTA pH 8.0 ), at $50 \mathrm{~V}$ for $5 \mathrm{~h}$ and visualized by UV illumination after staining in ethidium bromide. One kb DNA Ladder (Fermentas, Lituania) was used as a DNA size marker.

RAPD bands were scored as binary data [present (1) or absent (0)] for each strain. Phylogenetic cluster analyses of the binary matrix were performed using the software NTSYSpc version 2.02 (Exeter Software, Setauket, NY, USA) by the UPGMA with Jaccard's similarity. The matrix was also analyzed by simple matching (SM) and Yule (Y) similarity coefficients in NTSYS.

\subsection{Metabolite extraction}

Metabolite extractions were performed on the 14-days-old DRYES cultures. The extraction protocol used was a micro-scale extraction method modified for Alternaria metabolites (Andersen et al., 2005). Three agar plugs ( $6 \mathrm{~mm}$ in diameter) were cut from the center of the three colonies and the nine plugs were placed in a 2-ml-screwtop vial. Then $1.0 \mathrm{ml}$ ethyl acetate containing $1 \%$ formic acid (vol/ vol) was added to each vial and the vial was placed at $-18{ }^{\circ} \mathrm{C}$ for a minimum of $12 \mathrm{~h}$. The plugs were extracted within ultrasound for $60 \mathrm{~min}$ in a Branson 3210 water bath (Ultrasonics Corporation, Danbury, CT, USA). The ethyl acetate extract was transferred to a clean 2-ml vial, evaporated to dryness in a rotary vacuum concentrator (Christ, Gefriertrocknungsanlagen GmbH, Osterode am Harz, Germany), re-dissolved ultrasonically in $400 \mu \mathrm{l}$ methanol for $15 \mathrm{~min}$, and filtered through a $0.45-\mu \mathrm{m}$ filter (National Scientific Company, Rockwood, TN, USA) into a clean 2-ml vial prior to HPLC analysis. Keep the vials in the freezer $\left(-18^{\circ} \mathrm{C}\right)$ until HPLC analysis.

\subsection{HPLC-UV-VIS analysis}

The HPLC analyses were performed on a HP-1100 high performance liquid chromatograph (Agilent, Waldbronn Germany) equipped with an auto sampler injecting $3.0 \mu \mathrm{sample}^{-1}$ and a diode array detector

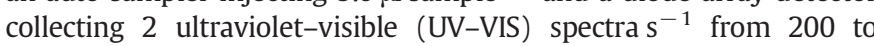
$600 \mathrm{~nm}$. Separations were done on a $100 \times 2 \mathrm{~mm}$ Luna $3 \mu \mathrm{m} \mathrm{C18(2)}$ 100 Å column (Phenomenex, Torrance, CA, USA) with a $4 \times 2 \mathrm{~mm} \mathrm{C18}$ (2) guard column (Phenomenex, Torrance, CA, USA). The column temperature was $40{ }^{\circ} \mathrm{C}$. The mobile phase consisted of a linear gradient starting at $85 \%$ water and $15 \%$ acetonitrile reaching $100 \%$ acetonitrile in $20 \mathrm{~min}$. 100\% acetonitrile was maintained for $5 \mathrm{~min}$. Thereafter, the gradient was returned to $15 \%$ acetonitrile in $3 \mathrm{~min}$ and allowed to equilibrate for $5 \mathrm{~min}$ before the next analysis. Both eluents contained $50 \mathrm{ppm}$ trifluoroacetic acid. The flow rate was $0.4 \mathrm{ml} \mathrm{min}^{-1}$. A homologous series of alkylphenones was analyzed as external retention time references and used to calculate a bracketed retention index (RI) for each detected peak (Frisvad and Thrane, 1987). Origin and preparation of fungal standards, such as altenuene, alternariols, altersolanol A, altertoxin I, erythroglaucin, tentoxin and tenuazonic acid, are given in Nielsen and Smedsgaard (2003). All solvents were HPLC grade, chemicals were analytical grade and the water was double distilled.

\subsection{Data treatment of metabolite profiles}

The raw HPLC data files, which are quantitative 2-D matrices ( $\mathrm{x}$ axis: time, Y-axis: wavelength, value in matrix: UV-VIS absorbance), were transferred from the HPLC to a standard PC and analyzed by an in-house written chemical image analysis (CIA) program (Hansen, 2003). No manipulations or peak selections were made before processing. Each HPLC file was processed first by a $\log _{10}$ scaling (to account for concentration differences among extracts), then a baseline correction and finally an alignment (to account for drift in baseline and retention time among identical metabolites in different runs) (Hansen, 2003). Each HPLC file was then compared to the other 29 HPLC files, pair-wise, using an algorithm described by Hansen (2003) giving a similarity value for each pair, which was entered into a new matrix. The resulting $30 \times 30$ similarity matrix was then used to calculate a dendrogram using WARD clustering method. Based on the result of the CIA, $a$ binary matrix was made manually by scoring each metabolite as binary data [present (1) or absent (0)] from the printed chromatograms and subjected to multivariate statistics using The Unscrambler version 9.2 (CAMO ASA, Oslo, Norway). This full manual metabolite matrix consisted of $61 \mathrm{X}$ variables (known and unknown metabolites) and 3 Y-variables (3 species names) for the 30 objects (fungal strains with confirmed ID and clustering according to ID). The matrix was analysed using Partial Least Squares Regression (PLS-R), which relates the variations in response variables (Y-matrix) to the variations of several predictors (X-matrix) (Wold et al., 2001).

\subsection{Cluster analysis of metabolite data}

A manual metabolite matrix was made and contained consistently produced metabolites with both known and unknown chemical structures. The binary matrix, consisting of 30 strains and 61 metabolites, was subjected to cluster analysis using NTSYS-pc version $2.11 \mathrm{~N}$ without standardization using Yule $(\mathrm{Y})$ as correlation coefficient and UPGMA as clustering method. The matrix was also analyzed by simple matching (SM) and Jaccard (J) similarity coefficients in NTSYS.

\subsection{Cluster analysis of all data}

A binary matrix was made by pooling morphological data (20 characters), molecular data (73 RAPD bands) and chemical data (53 metabolites) for the 30 Alternaria strains. The matrix was subjected to cluster analysis using NTSYS-pc version $2.11 \mathrm{~N}$ without standardization using Yule (Y) as correlation coefficient and UPGMA as clustering method. The matrix was also analyzed by simple matching (SM) and Jaccard $(\mathrm{J})$ similarity coefficients in NTSYS.

Each experiment was performed at least two times and data are expressed as the means (SE).

\section{Results}

\subsection{Morphology and cultural characterization}

When grown on PCA under standardized conditions, the 20 endophytic strains showed two different sporulation patterns that corresponded to the representative strains: one similar to the $A$. arborescens sporulation pattern (sporulation group 3, Simmons and Roberts, 1993) and one similar to A. tenuissima sporulation pattern (sporulation group 5, Simmons and Roberts, 1993) (Table 1 and Figs. 1 and 2, respectively). 
None of the endophytic strains gave a sporulation pattern similar to that of A. alternata, characterized by short primary conidiophores and chains that mainly branch from the conidial body by means of short secondary conidiophores. The color of A. alternata colonies on DRYES are primarily dark green. Neither did any of the endophytic strains yield sporulation patterns similar to those of the A. infectoria species-group, characterized by short primary conidiophores and conidia in branched chains with long secondary conidiophores. The color of the A. infectoria speciesgroup colonies on DRYES were white to grayish white.

Nine endophytic strains had sporulation patterns similar to that of the $A$. arborescens species-group, and were characterized by long (up to $200 \mu \mathrm{m}$ ) primary conidiophores bearing between 15 and 20 conidia in branched chains at the top (Fig. 1). The branching predominately occurred from the conidial apex and the primary conidium could often be twice as long $(30-50 \mu \mathrm{m})$ as the subsequent conidia and having geniculate secondary conidiophore (up to $30 \mu \mathrm{m}$ ) with several loci. On PCA, the nine strains of the A. arborescens speciesgroup showed the characteristic alternating heights of growth rings, while on DRYES the color of the colonies varied from dark green to grayish green. Strains P85B, P85C, P85D, R42A and T50C1 were very similar, while A-MELO and P85A were not as branched as the first. The last two strains (T65A and R89A) deviated in both micro- and macro-morphological characteristics from the representative strains. Strain R89A produced fewer conidia per primary conidiophore and colonies on DRYES were sulcate and lighter green in color. Strain T65A had a higher percentage of its secondary conidiophores originating from the conidium body, darker conidial walls and colonies were dark green and heavily wrinkled on DRYES.

Eleven endophytic strains identified as belonging to the A. tenuissima species-group had conidia in unbranching chains, borne on short primary conidiophores (Fig. 2). If branching occurred in these strains, short $(6-12 \mu \mathrm{m})$ simple secondary conidiophores would usually originate from the conidial body and not from the apex. The endophytic strains of the A. tenuissima species-group had mostly green or light green colonies on DRYES. Strains M44B, R68B, T65B, VP13B2B and VP13B2B2 looked similar with more stubby conidia compared to strains R94A2, VP12B1A, VP12B2A and VP12A5B that have more elongated conidia. However, two strains, M44C and T65D, differed more in micromorphological characteristics. Strain M44C sometimes produced long (up to $40 \mu \mathrm{m}$ ), but simple, apical secondary conidiophores. Strain T65D sometimes produced up to four short, simple secondary conidiophores from the central cells of a conidium giving rise to chains of mostly two new conidia.

\subsection{Molecular RAPD characterization}

Only 30 out of the 32 strains were subjected to RAPD analyses, excluding the two strains representing the A. infectoria species-groups. RAPD-PCR of the grapevine Alternaria endophytes as well as reference strains yielded a total of 77 reproducible RAPD fragments. Minor fragments (i.e., those less intensely stained by ethidium bromide) were not reproducible and were not scored. The RAPD fragment patterns showed a high degree of variation between strains of the $A$. arborescens and strains of the A. tenuissima species-group, including the reference strains. The RAPD analyses also showed a high degree of pattern similarity within the species or species-groups. Fig. 3 shows the result of the RAPD analysis with OPA 9 primer for all strains except the 2 strains belonging to the $A$. infectoria species-group.

Cluster analysis based on RAPD similarities showed two distinct groups of strains similar to the A. tenuissima species-group (cluster $\mathrm{B}$ ) and the A. arborescens species-group (cluster A) (Fig. 4). These species-groups were well separated and supporting the morphological identification. The $A$. arborescens species-group showed $47 \%$ similarity (Fig. 4); only two endophytic strains (T65A and R89A) clustered
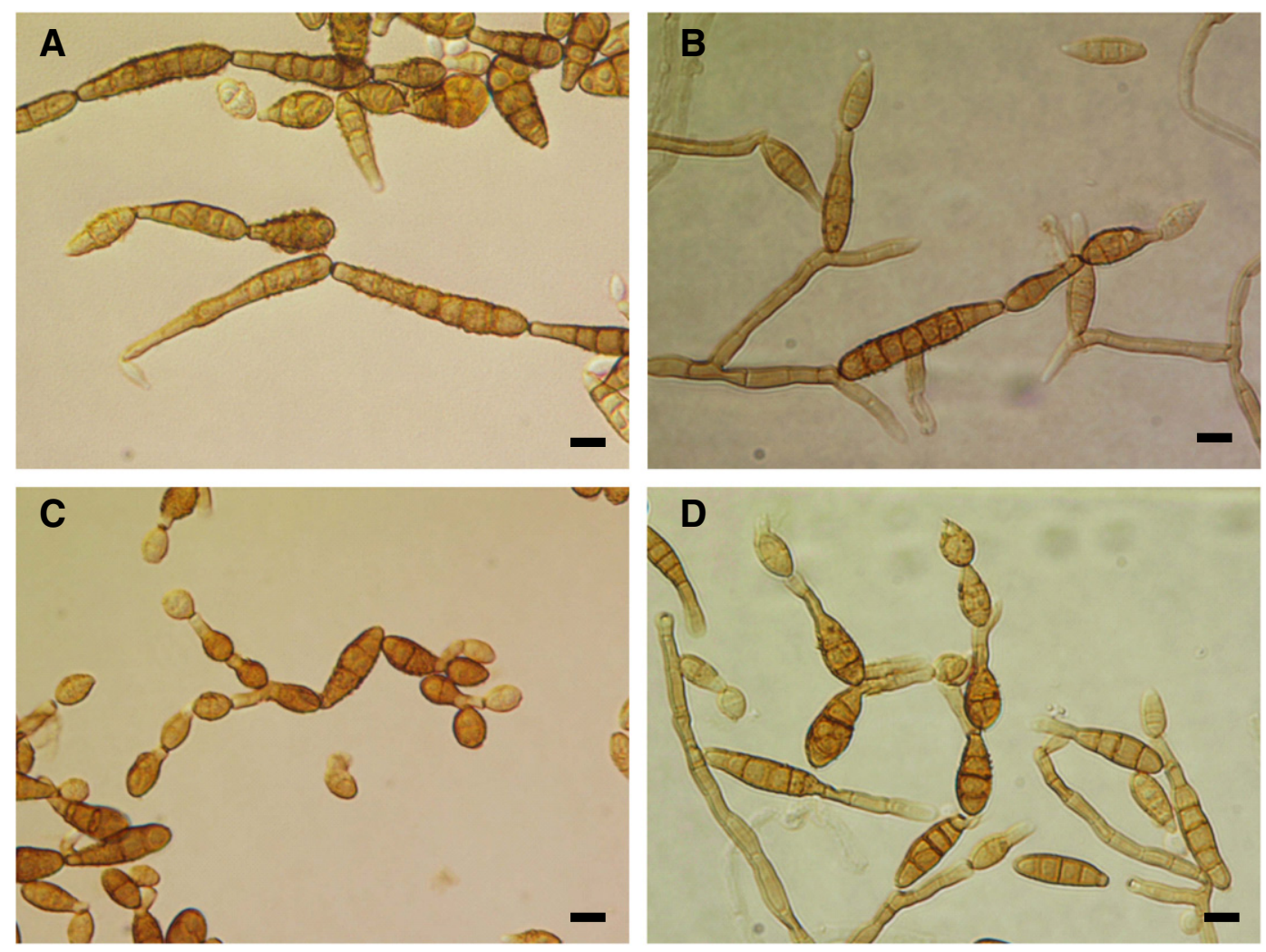

Fig. 1. Sporulation pattern on 7-day old PCA cultures of the Alternaria arborescens species-group. A and C: sporulation patterns of two endophytic strains belonging to A. arborescens species-group (P85A and T50C1, respectively); B and D: sporulation patterns of two representative strains of the A. arborescens species-group (BA1343 and BA1382, respectively). Bars correspond to $10 \mu \mathrm{m}$. 

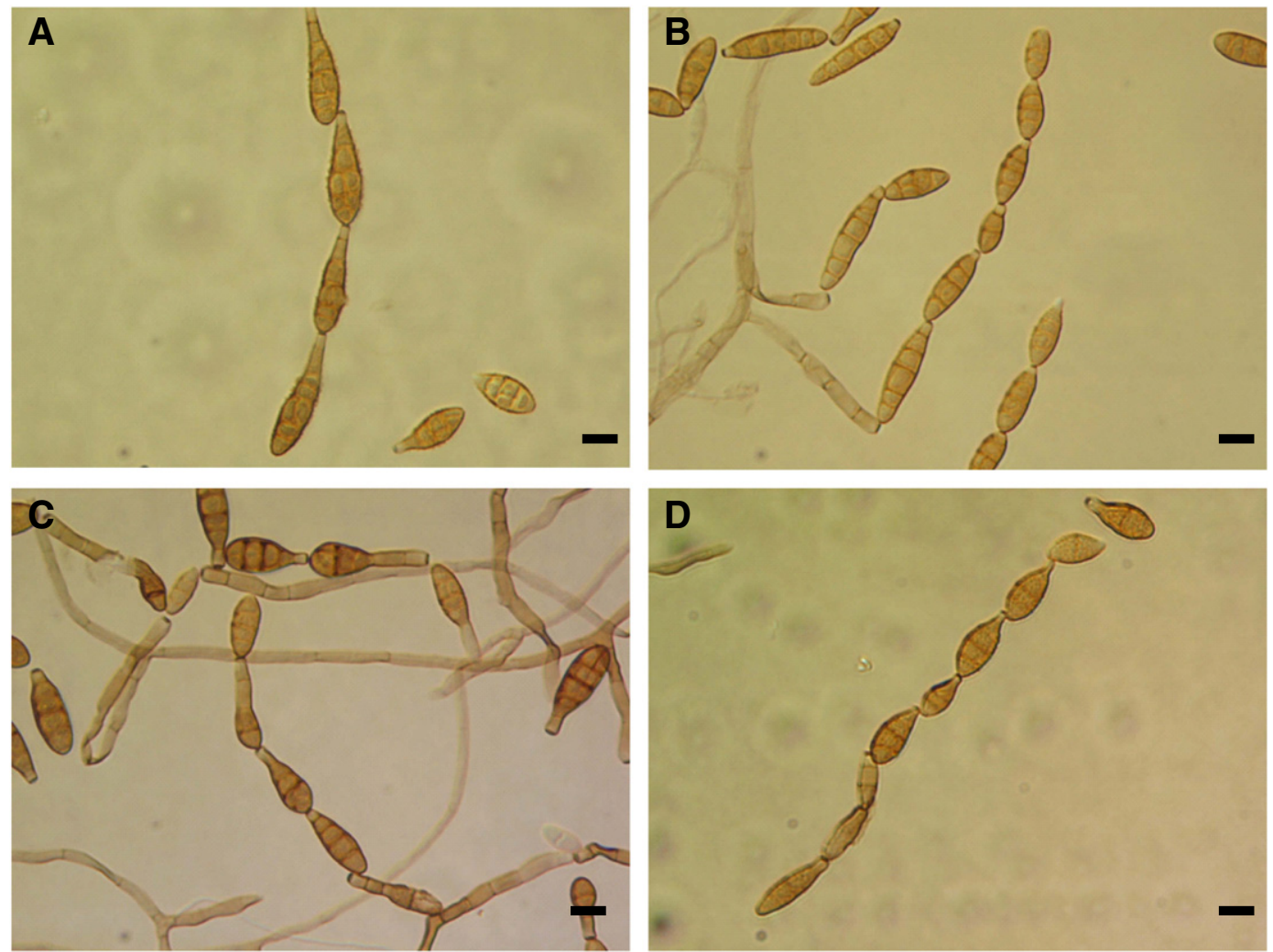

Fig. 2. Sporulation pattern on 7-day old PCA cultures of the Alternaria tenuissima species-group. A and C: sporulation patterns of two endophytic strains belonging to A. tenuissima species-group (R94A2 and VP12B2A); B and D: sporulation patterns of two representative strains of the A. tenuissima species-group (BA853 and BA925, respectively). Bars correspond to $10 \mu \mathrm{m}$.

separately and this result is correlated with morphological observations. Strains of the A. alternata and A. tenuissima species-groups clustered together with $52 \%$ similarity in RAPD fragment patterns (Fig. 4). Within cluster B, the A. alternata strains clustered together, but separately (cluster $\mathrm{C}$ ) from the majority endophytic $A$. tenuissima strains at $65 \%$ similarity with the exception of the representative strains BA925 (A. tenuissima species-group), which clustered with the $A$ alternata group. In the $A$. tenuissima species-group, endophytic strains and representative strain BA953 clustered at 65\% similarity, except representative strains BA879 (A. tenuissima species-group), which clustered outside the main cluster. The endophytic strains (M44C and T65D) clustered separately from tenuissima species-group in agreement with morphological results.

\subsection{Chemical characterization}

The result of the automated and unbiased CIA of 30 Alternaria extracts (excluding the strains in the A. infectoria species-group) is shown in Fig. 5. The analysis is based on chromatograms (HPLC files) of raw fungal extracts that contained compounds from the growth media (e.g., chloramphenicol and dichloran), impurities from extraction solvents, fungal-specific (e.g., ergosterol), speciesspecific, and strain-specific metabolites. The dendrogram shows two main cluster, A and B. Cluster B contains all but one of the A. tenuissima species-group strains and one $A$. arborescens species-group strain (P85A), but only one of the representative A. tenuissima strains (BA853). Cluster A contains one minor cluster (A1) with two A.

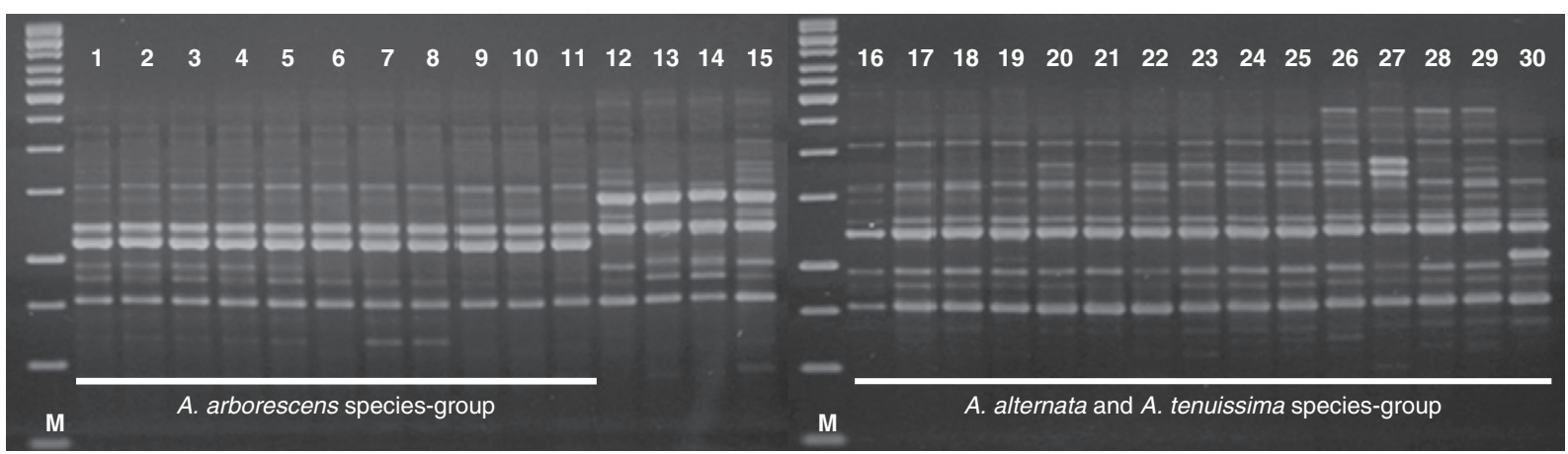

Fig. 3. DNA banding patterns from random amplified polymorphisms DNA (RAPD) analysis with primer OPA9 of 20 endophytic Alternaria isolates collected from grapevine and 10 representative A. arborescens, A. tenuissima, and A. alternata strains. Lanes 1-11: A. arborescens species-group (P85A, T50C1, R42A, BA1343, BA1422, P85B, P85C, P85D, A.MELO, BA961, and BA1382, respectively); lanes 16, 17, and 20: A. alternata (BA923, BA924, and BA922, respectively); lanes 18, 19, and 21-30: A. tenuissima species-group (BA925, BA879, T65B, BA853, R68B, VP13B2B, VP13B2B2, M44B, VP12B2A, R94A2, VP12A5B, and VP12B1A, respectively). Lanes 12-15: M44C, T65A, R89A and T65D (strains with deviant morphological characters). M: $1 \mathrm{~Kb}$ DNA Ladder (Fermentas, Lituania). 


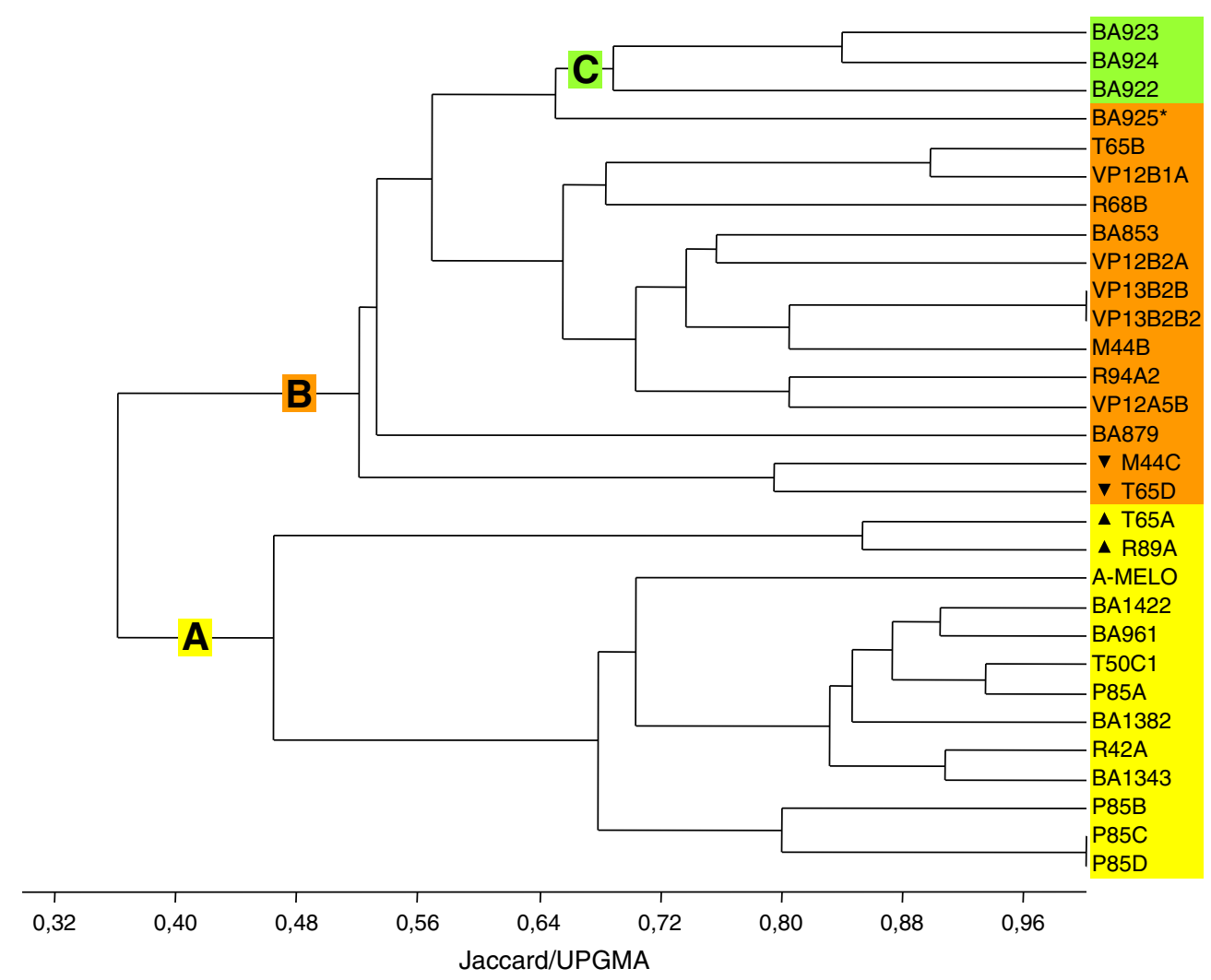

Fig. 4. Dendrogram based on RAPD profiles of 20 endophytic Alternaria strains and 10 strains of representative Alternaria species-groups using Jaccard similarity coefficient and UPGMA analysis. The primers OPA9, OPA13, OPR-02 and OPR-12 used were. A. alternata strains (cluster C in green), strains belonging to the A. tenuissima species-group (cluster B in orange) and strains belonging to the A. arborescens species-group (cluster C in yellow). Strains marked with $\mathbf{\Delta}$ or $\boldsymbol{\nabla}$ are atypical compared to their species group.

arborescens species-group strains (P85B and P85C) and one the $A$. tenuissima species-group strain (M44B) and one major cluster (A2) with all but one of $A$. arborescens species-group strains, all the A. alternaria strains and the remaining two representative A. tenuissima strains (BA879 and BA925).

A Partial Least Squares Regression (PLS-R) was made to select species-specific metabolites and deselect common and inconsistently produced metabolites. The matrix was constructed from the 30 HPLC chromatograms as a binary matrix based on the presence or absence of 61 selected metabolites that were produced in high concentration and that had distinct UV-VIS spectra. The plot in Fig. 6 shows the calculated model, which explains $52 \%$ of the fungal identity (y-data) and $26 \%$ of the chemical diversity ( $x$-data) on the first two axes out of the four axes that constituted the model. The 61 metabolites were represented in the plot by metabolite name or their RI values when the metabolite is of unknown structure. The model in Fig. 6 gave the groupspecific metabolites by arranging them along a line (arrow) from the center of the coordinate system to the given species-group. By plotting the PLS components one can view main associations between $\mathrm{X}$-variables (metabolites) and Y-variables (strain ID), and also interrelationships within X-and Y-data. The closer a metabolite is to the arrowhead and the species-group name, the more specific it is and the larger a percentage of the strains in the given species produce it. For example, all the A. alternata strains produced the metabolites with RI value 798 and 903 . Metabolites that are located between two arrows are common to both species-groups, whereas metabolites located diametrically opposite a arrow are not produced by the given species-group. Also, alternariol (852), alternariol monomethyl ether (987) and metabolite 667 are commonly produced by both A. alternata and strains belonging to the $A$. arborescens species-group, but produced more scarcely by $A$. tenuissima species-group strains. Altersetin (1374) and 722, on the other hand, are common to both $A$. arborescens and A. tenuissima species-groups, but not found in $A$. alternata. Metabolites that are either produced by all strains or produced by few strains would be located in the center of the coordinate system.

\subsection{Endophyte-specific metabolites}

No metabolites specific to all the 20 endophytic strains were found among the 61 selected metabolites. However, some metabolites (marked in bold green in Fig. 6) were found to be produced only by the endophytic strain, though inconsistently. The majority of the metabolites could be identified with known chemical structure, based on their UV-VIS spectra and compared to the metabolite standards (Nielsen and Smedsgaard, 2003). In particular, none of the representative A. alternata strains produce tenuazonic acid (TeA), while the $A$. tenuissima and A. arborescens strains produce it consistently (100\% and $78 \%$, respectively). Furthermore, the two species-groups are characterized by a broad variety of Alternaria known metabolites (e.g., altenuene, alternariol, alternariol monomethyl ether), new metabolite, such as altersetin, extracted from endophytic Alternaria strains, and unknown metabolite. None of the 30 Alternaria strains were found to produce diketopiperazines on the media used in this study.

\subsection{Polyphasic characterisation}

Fig. 7 shows the resulting dendrogram of a cluster analysis made on the pooled binary matrix of morphological, molecular and chemical data. The dendrogram shows A. alternata (cluster C) is a tight group with approximate $91 \%$ overall similarity. One representative strain of the A. tenuissima species-group (BA879) is an outlier to this cluster. The strains belonging to the $A$. arborescens speciesgroup (cluster A) represent a variable group with about $70 \%$ 
0

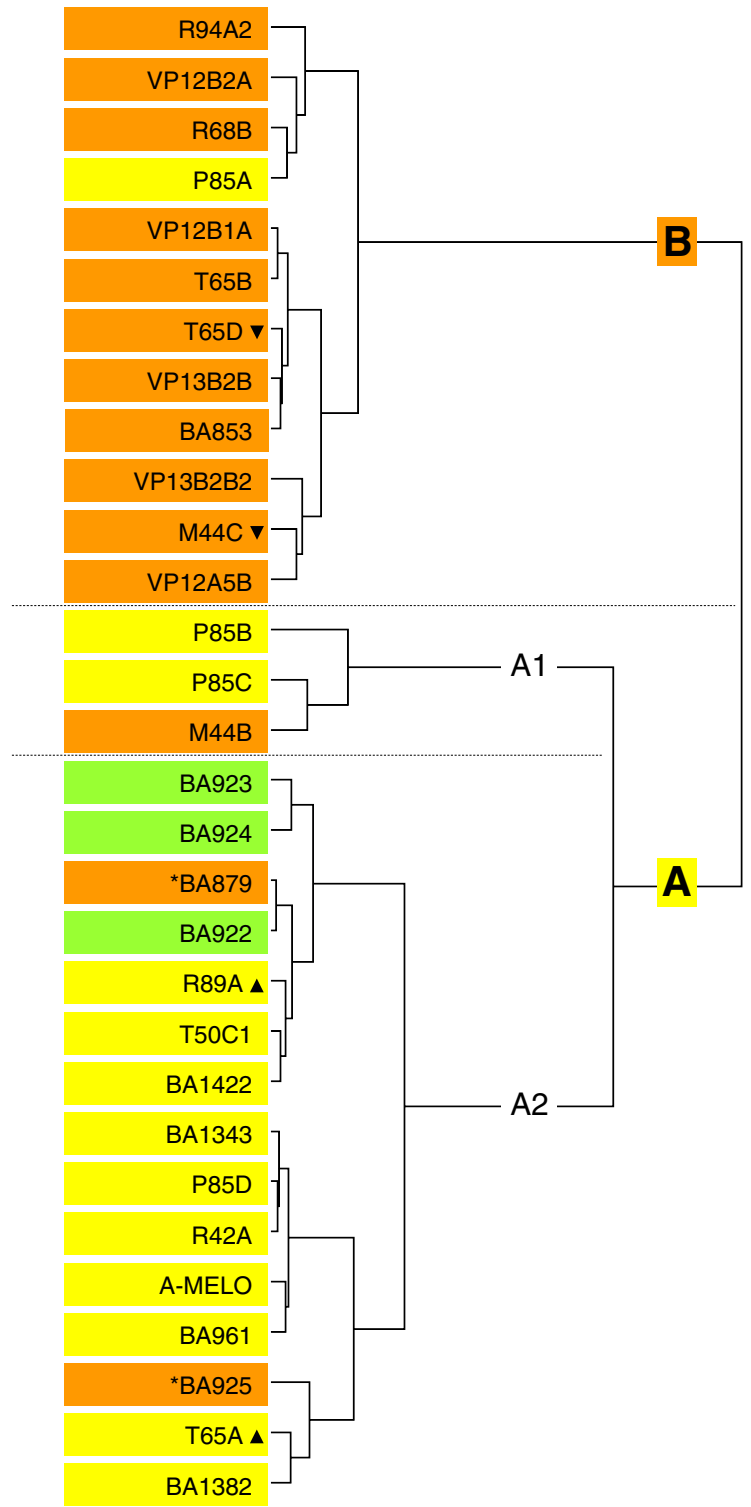

Fig. 5. Dendrogram based on an automated CIA of all metabolites of 20 endophytic Alternaria strains and 10 strains of representative Alternaria species-groups using the Ward clustering method. Arbitrary scale. A. alternata strains (cluster C in green), strains belonging to the A. tenuissima species-group (cluster B in orange) and strains belonging to the $A$. arborescens species-group (cluster $C$ in yellow). Strains marked with $\boldsymbol{\Delta}$ or $\boldsymbol{\nabla}$ are atypical compared to their species group.

similarity. Two endophyte strains (R89A and T65A) stay together as a sister cluster to the main A. arborescens cluster. Strains belonging to the A. tenuissima species-group (cluster B) are a more variable group with an overall similarity of $70 \%$. Three endophyte strains (M44C and T65D) stay together as a sister cluster to the main $A$. tenuissima cluster with M44B as an outlier.

\section{Discussion}

Most studies on identification of endophytic fungi have been conducted by using a combination of morphological and molecular methods. Since endophytes are said to produce additional bioactive metabolites (Tan and Zou, 2001), a polyphasic approach including metabolite profiling should give a good basis to classify this type of fungi (Frisvad et al., 2008).
In this work, a polyphasic approach has been set up for the characterization of 20 grapevine endophytic strains belonging to the genus Alternaria.

Regarding the first objective of this research, i.e., the evaluation of Alternaria endophytes by micro-morphological traits, the use of PCA incubated under standardized conditions and the comparison to representative strains, showed that the 20 endophytic strains belonged to either the $A$. arborescens or the A. tenuissima species-group (Andersen and Thrane, 1996; Andersen et al., 2001) according to the sporulation patterns proposed by Simmons and Roberts (1993). The use of different culture media (DRYES, MEA, PDA, DG18) and the evaluation of the macro-morphological characteristics, already used to discriminate between pathogen Alternaria species (Andersen et al., 2005), proved to have taxonomic value also for endophytes, corroborate the results obtained by micro-morphological observations. By means of the association of micro- and macromorphological data, seven endophyte strains could be grouped with the $A$. arborescens species-group and nine belonged to the $A$. tenuissima species-group. None of the endophytic strains recovered from grapevine produced sporulation patterns or metabolite profiles identical to those of $A$. alternata or the A. infectoria species-group. The results showed that most of the endophytic strains grouped with known Alternaria taxa isolated as saprophytes from other substrates than grapevines. Only four endophytic strains showed characteristics of their own. The couples T65A-R89A ( $\boldsymbol{\Delta}$ in Figs. 4, 5 and 7) and M44C-T65D ( $\boldsymbol{\nabla}$ in Figs. 4, 5 and 7) each showed different microand macro-morphological characteristics and may represent distinct and more distant taxa, one in each species-group.

The second part of the polyphasic characterization of Alternaria endophytes regarded the individuation of an appropriate molecular method to differentiate the strains, complementing morphological observations. To find suitable genes to analyze and compare sequences of 'small spored' Alternaria is not simple (Bruns et al., 1991). It is known that the analysis of the sequences coding for ITS1 and ITS2 regions is not sufficiently variable to estimate a phylogeny among the 'small spored' Alternaria (Kusaba and Tsuge, 1995) as well as the use of EF- $1 \alpha$, CAL, CHS, and THN sequences (Roberts et al., 2000; Pryor and Michailides, 2002; Hong et al., 2006; Andrew et al., 2009). Moreover, as MtLSU sequence data resulted satisfactorily variable to differentiate the 'large-spored' species of Alternaria from the 'small-spored' ones, the analysis of this gene region do not allow to segregate among 'small-spored' strains (Peever et al., 2004). However, RAPD technique, which characterizes random priming sites across the entire genome, consents to evidence a high genetic variability among 'small-spored' Alternaria; such variability is coherent with morphological, physiological and chemical observations (Roberts et al., 2000). In the present study, RAPD fingerprint pattern analysis, allowed to demonstrate that grapevine endophytes belonging to the $A$. arborescens species-group are molecularly distinct from endophytes belonging to the $A$. tenuissima species-group (Fig. 4). These results are in agreement with those already reported by Roberts et al. (2000) and by Pryor and Michailides (2002). Moreover, cluster analysis of RAPD profiles permitted to discriminate, into A. tenuissima species-groups, representative strains belonging to A. alternata, whereas they did not separate in the study by Pryor and Michailides (2002). Results achieved by molecular methods also confirm the low similarity of the endophytic strains marked with $\Delta$ (T65A-R89A) and $\boldsymbol{\nabla}$ (M44C-T65D) within their species group.

To complete the endophyte fungal characterisation, chemotaxonomy based on secondary metabolite profiles was employed. Metabolite profiling is a relevant tool for characterization of endophytic Alternaria spp., because they are supposed to produce chemically different and bioactive compounds (Quiao et al., 2007; Aly et al., 2008). The role of these compounds, e.g. altersetin and altenuisin, antibiotics from endophytic Alternaria spp. (Hellwig et al., 2002; Cota et al., 2008 ) and others of yet chemically unknown structure, is waiting to 


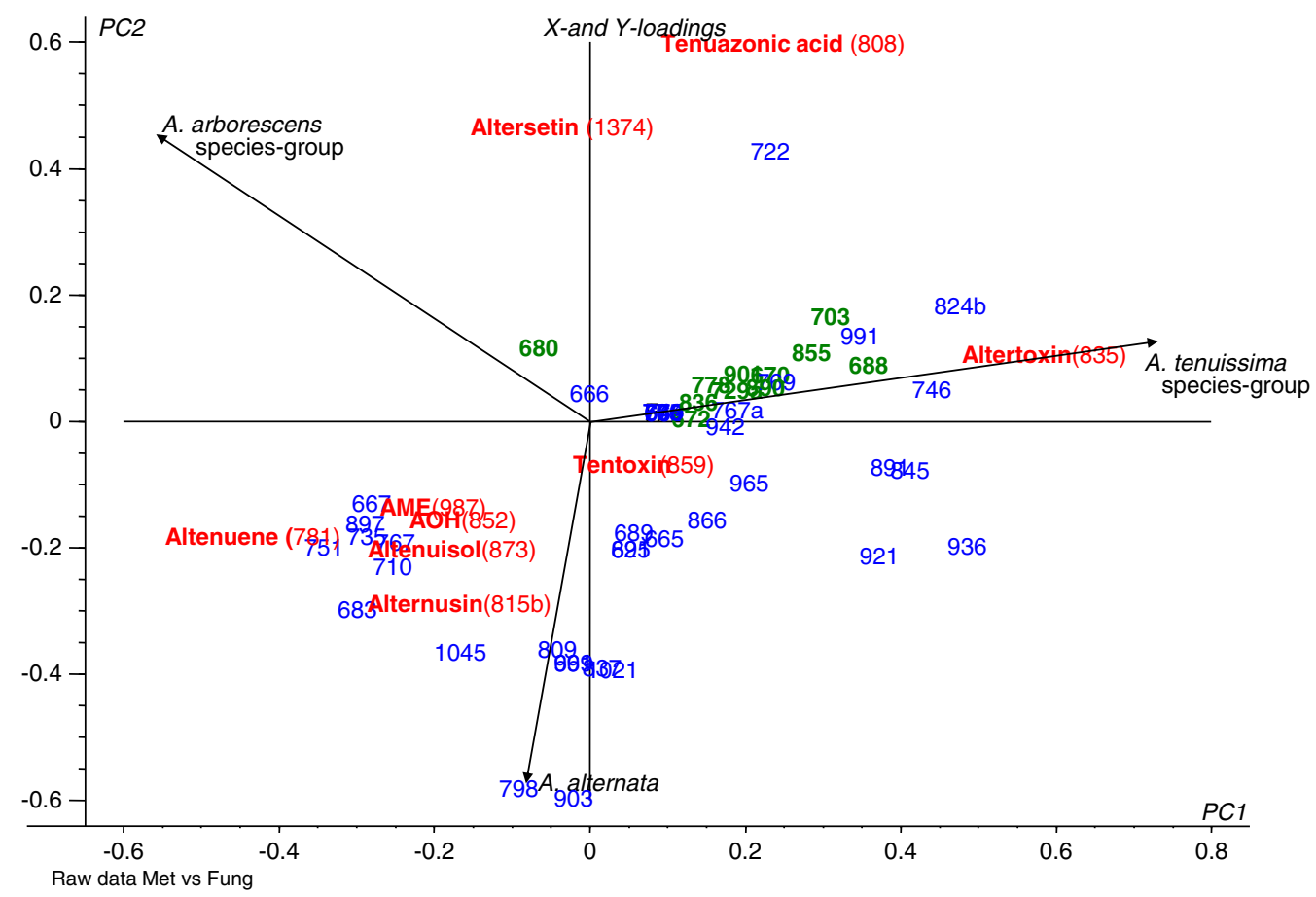

Fig. 6. Loadings plot based on a PLS-R of the manual metabolite matrix of 61 metabolites of 20 endophytic Alternaria strains and 10 strains of representative Alternaria species-groups. Known metabolites are given by their name and RI value (in bold red) and unknown metabolites are given only by their RI value (in blue). Endophyte-specific metabolites are marked in bold green. Axes are principal components 1 and 2 .

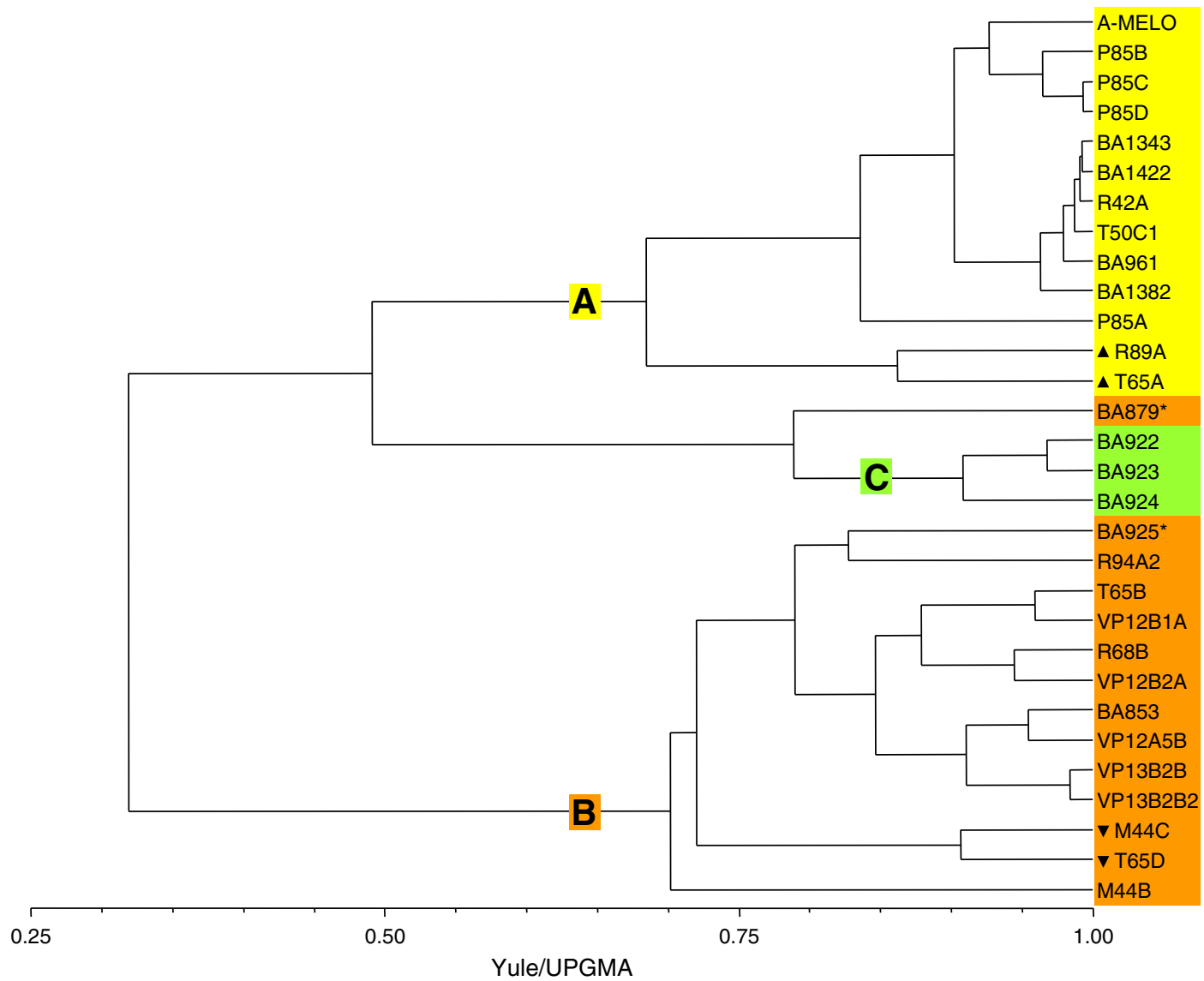

Fig. 7. Dendrogram based on morphological characters, metabolite profiles and RAPD profiles of 20 endophytic Alternaria strains and 10 strains of representative Alternaria speciesgroups using Yule similarity coefficient and UPGMA analysis. A. alternata strains (cluster C in green), strains belonging to the A. tenuissima species-group (cluster B in orange) and strains belonging to the $A$. arborescens species-group (cluster $C$ in yellow). Strains marked with $\mathbf{\Delta}$ or $\mathbf{\nabla}$ are atypical compared to their species group. 
be investigated. In our study, metabolite profile analyses resulted species-characteristic and permitted to assign the 20 grapevine endophytes in two main groups, the first having metabolic profile similar to $A$. arborescens species-group, the second having metabolic profile similar to A. tenuissima species-group, also confirming the presence of atypical strains ( $\boldsymbol{\Delta}$ and $\mathbf{\Delta}$ ). Endophytic strains belonging to these two groups revealed a more complex metabolite profile characterized by more metabolites than those produced by A. alternata. Generally, endophytes belonging to $A$. arborescens and $A$. tenuissima speciesgroups produced the same known metabolites typical of these two groups. Especially, the production of tenuazonic acid differentiated them from other 'small-spored' Alternaria, such as A. alternata and the A. infectoria species-group (Andersen et al., 2002) that typically produces altenuene, alternariol, alternariol monomethyl ether and altertoxin I (Bottalico and Logrieco, 1992). It has been indicated that tenuazonic acid, and other known secondary metabolites produced by Alternaria spp., demonstrated severe growth-inhibiting activity and alteration of cytoplasmatic structurals of plant host (Bottalico and Logrieco, 1992). Nevertheless, particular toxicological risks are caused in relatively few plant products: tomatoes, apples, citrus and related processed products (Bottalico and Logrieco, 1992).

Among the secondary metabolites produced by the 20 Alternaria endophytes, many are of unknown chemical structure. Considering that literature reported about the effectiveness of Alternaria endophytes against important grapevine pathogens (Musetti et al., 2006; 2007), it should be interesting to elucidate the chemical structure of Alternaria unknown metabolites and to evaluate them as new biological method in the control of grapevine diseases. Moreover, the complete knowledge of endophyte chemical characteristics could be useful as chemical marker for a more precise segregation of endophytic and pathogenic Alternaria strains.

Results obtained by the polyphasic approach described in this work, indicate that the majority of grapevine endophytic strains clearly belongs to the representative Alternaria species-groups, with the exception of the strains M44C and T65D ( $\mathbf{\nabla}$ ) and R89A and T65A ( $\mathbf{\Delta})$ that resulted distant; so they could be considered as different taxa.

Concluding, our data demonstrate that grapevine is associated with a different Alternaria endophyte community. The combination of microscopy, isolation of pure cultures, molecular and chemical analyses, yielded comprehensive information about the identity, diversity, and phylogeny of these microorganisms, confirming that Alternaria endophytes, may constitute the dominant fungal consortium in grapevine tissues.

\section{Acknowledgements}

The authors would like to thank Dr. K.F. Nielsen, DTU, for assistance with the chemical analyses and Prof. Ruggero Osler for text and language revision.

This research was supported by Area Science Park (Italy) 'Sister' Project, by Arsia-Regione Toscana (Italy), and by Tenuta Villanova (Farra d'Isonzo, GO, Italy).

\section{References}

Aly, A.H., Edrada-Ebel, R.A., Indriani, I.D., Wray, V., Muller, W.E.G., Totzke, F., Zirrgiebel U., Schachtele, C., Kubbutat, M.H.G., Lin, W.H., Proksch, P., Ebel, R., 2008. Cytotoxic metabolites from the fungal endophyte Alternaria sp. and their subsequent detection in its host plant Polygonum senegalense. J. Nat. Prod. 71, 972-980.

Andersen, B., Thrane, U., 1996. Differentiation of Alternaria infectoria and Alternaria alternata based on morphology, metabolites profiles and cultural characteristics. Can. J. Microbiol. 42, 685-689.

Andersen, B., Krøger, E., Roberts, R.G., 2001. Chemical and morphological segregation of Alternaria alternata, A. gaisen and A. longipes. Mycol. Res. 105, 291-299.

Andersen, B., Krøger, E., Roberts, R.G., 2002. Chemical and morphological segregation of Alternaria arborescens, A. infectoria and A. tenuissima species-groups. Mycol. Res. $106,170-182$.
Andersen, B., Hansen, M.E., Smedsgaard, J., 2005. Automated and unbiased image analyses as tools in phenotypic classification of small-spored Alternaria spp. Phytopathology 95, 1021-1029.

Andersen, B., Sørensen, J.L., Nielsen, K.F., Gerrits van den Ende, B., de Hoog, S., 2009. A polyphasic approach to the taxonomy of the Alternaria infectoria species-group. Fungal Genet. Biol. 46, 642-656.

Andrew, M., Peever, T.L., Pryor, B.M., 2009. An expanded multilocus phylogeny does not resolve morphological species within the small-spored Alternaria species complex. Mycologia 101, 95-109.

Azevedo, J.L., Maccheroni Jr., W., Pereira, J.O., de Araujo, W.L., 2000. Endophytic microorganisms: a review on insect control and recent advances on tropical plants. Electron. J. Biotechnol. 3, 1-36.

Bottalico, A., Logrieco, A., 1992. Alternaria plant disease in Mediterranean countries and associated mycotoxins. In: Chelkowski, J., Visconti, A. (Eds.), Alternaria Biology, Plant Disease and Metabolites. Elsevier, Amsterdam, The Netherlands, pp. 209-232.

Bruns, T.D., White, T.J., Taylor, J.W., 1991. Fungal molecular systematic. Annu. Rev. Ecol. Syst. 22, 525-564.

Bulgari, D., Casati, P., Crepaldi, P., Daffonchio, D., Quaglino, F., Brusetti, L., Bianco, P.A. 2011. Restructuring of endophytic bacterial communities in grapevine yellowsdiseased and recovered Vitis vinifera L. plants. Appl. Environ. Microbiol. 77, 5018-5022.

Cooke, D.E.L., Forster, J.W., Jenkins, P.D., Jones, D.G., Lewis, D.M., 1998. Analysis of intraspecific and interspecific variation in the genus Alternaria by the use of RAPD-PCR. Ann. Appl. Biol. 132, 197-209.

Cota, B.B., Rosa, L.H., Caligiorne, R.B., Rabello, A.L., Teles, A., Alves, T.M., Rosa, C.A., Zani, C.L., 2008. Altenusin, a biphenyl isolated from the endophytic fungus Alternaria sp., inhibits trypanothione reductase from Trypanosoma cruzi. FEMS Microbiol. Lett. 285, 177-182.

Dugan, F.M., Lupien, S.L., 2002. Filamentous fungi quiescent in seeds and culm nodes of weedy and forage grass species endemic to the Palouse Region of Washington and Idaho. Mycopahologia 156, 31-40.

Dugan, F.M., Lupien, S.L., Grove, G.G., 2002. Incidence, aggressiveness and in planta interactions of Botrytis cinerea and other filamentous fungi quiescent in grape berries and dormant buds in Central Washington State. J. Pythopathol. 150, 375-381.

Frisvad, J.C., 1983. A selective and indicative medium for groups of Penicillium viridicatum producing different mycotoxins on cereals. J. Appl. Bacteriol. 54, 409-416.

Frisvad, J.C., Thrane, U., 1987. Standardized high-performance liquid chromatography of 182 mycotoxins and other fungal metabolites based on alkylphenone retention indices and UV-VIS spectra (diode array detection). J. Chromatogr. 404, 195-214.

Frisvad, J.C., Andersen, B., Thrane, U., 2008. The use of secondary metabolite profiling in chemotaxonomy of filamentous fungi. Mycol. Res. 112, 231-240.

Grisan, S., Martini, M., Musetti, R., Osler, R., 2011. Development of a molecular approach to describe the diversity of fungal endophytes in either phytoplasma-infected, recovered or healthy grapevines. Bull. Insectol. 64, 207-208.

Guo, L.D., Xu, L., Zheng, W.H., Hyde, K.D., 2004. Genetic variation of Alternaria alternata, an endophytic fungus isolated from Pinus tabulaeformis as determined by random amplified microsatellites (RAMS). Fund. Div. 16, 53-65.

Hansen, M.E. 2003. Indexing and analysis of fungal phenotypes using morphology and spectrometry. Ph.D. thesis. ISSN 0909-3192, IMM, DTU, Denmark.

Hellwig, V., Grothe, T., Mayer-Bartscmid, A., Endermann, R., Geschke, F.U., Henkel, T., Stadler, M., 2002. Altersetin, a new antibiotic from cultures of endophytic Alternaria spp. Taxonomy, fermentation, isolation, structure elucidation and biological activities. Antibiot. 55, 881-892.

Hong, S.G., Liu, D., Pryor, B.M., 2005. Restriction mapping of the IGS region in Alternaria spp. reveals variable and conserved domains. Mycol. Res. 109, 87-95.

Hong, S.G., Maccaroni, M., Figuli, P.J., Pryor, B.M., Belisario, A., 2006. Polyphasic classification of Alternaria isolated from hazelnut and walnut fruit in Europe. Mycol. Res. 110, $1290-1300$.

Kornerup, A., Wanscher, J.H., 1978. Methuen Handbook Of Color. E. Methuen, London, U. K.

Kortekamp, A., 1997. Epicoccum nigrum Link: a biological control agent of Plasmopara viticola (Berk. et Curt.) Berl. et De Toni. Vitis 36, 215-216.

Kusaba, M., Tsuge, T., 1995. Phologeny of Alternaria fungi known to produce hostspecific toxins on the basis of variation in internal transcribed spacers of ribosomal DNA. Curr. Genet 28, 491-498.

Lecellier, G., Silar, P., 1994. Rapid methods for nucleic acids extraction from Petri dish-grown mycelia. Curr. Genet 25, 122-123.

Martini, M., Musetti, R., Grisan, S., Polizzotto, R., Borselli, S., Pavan, F., Osler, R., 2009 DNA-dependent detection of the grapevine fungal endophytes. Plant Dis. 93, 993-998.

Mostert, L., Crous, P.W., Petrini, O., 2000. Endophytic fungi associated with shoots and leaves of Vitis vinifera, with specific reference to the Phomopsis viticola complex. Sydowia 52, 46-58.

Musetti, R., Vecchione, A., Stringher, L., Borselli, S., Zulini, L., Marzani, C., D'Ambrosio, M., Sanità di Toppi, L., Pertot, I., 2006. Inhibition of sporulation and ultrastructural alterations of grapevine downy mildew by the endophytic fungus Alternaria alternata. Phytopathology 96, 689-698.

Musetti, R., Polizzotto, R., Vecchione, A., Borselli, S., Zulini, L., D'Ambrosio, M., Sanità d Toppi, L., Pertot, I., 2007. Antifungal activity of diketopiperazines extracted from Alternaria alternata against Plasmopara viticola: An ultrastructural study. Micron 38, 643-650.

Nielsen, K.F., Smedsgaard, J., 2003. Fungal metabolite screening: database of 474 mycotoxins and fungal metabolites for dereplication by standardised liquid chromatography-UVmass spectrometry methodology. J. Chromatogr. 1002, 111-136.

Peever, T.L., Su, G., Carpenter-Boggs, L., Timmer, L.W., 2004. Molecular systematics of citrus-associated Alternaria species. Mycologia 96, 119-134. 
Polizzotto, R., D'Agostin, S., Grisan, S., Assante, G., Pertot, I., Andersen, B., Musetti, R. 2009. Attività di ceppi endofitici di Alternaria spp. nel controllo di Plasmopara viticola. J. Plant Pathol. 91 (4 Supplementum), 79-80.

Pryor, B.M., Bigelow, D.M., 2003. Molecular characterization of Embellisia and Nimbya species and their relationship to Alternaria, Ulocladium and Stemphylium. Mycologia 95, 1141-1154.

Pryor, B.M., Michailides, T.J., 2002. Morphological, pathogenic, and molecular characterization of Alternaria isolates associated with Alternaria late blight of pistachio. Phytopathology 92, 406-416.

Quiao, L.-R., Lin, Y. Gao, -M., Zhao, P.-J. Kang, Q-J., Shen, Y.-M., 2007. Tricycloalternarene derivatives produced by an endophyte Alternaria alternata isolated from Maytenus hookeri. J. Basic Microbiol. 47, 340-343.

Roberts, R.G., Reymond, S.T., Andersen, B., 2000. RAPD fragment pattern analysis and morphological segregation of small-spored Alternaria species and species groups. Mycol. Res. 104, 151-160.

Samson, R.A., Hoekstra, E.S., Frisvad, J.C., Filtenborg, O., 2002. Introduction to food- and air borne fungi. Centraalbureau voor Schimmelcultures, Utrecht, The Netherlands. pp 378-382.
Schena, L., Ippolito, A., Zahavi, T., Cohen, L., Nigro, F., Droby, S., 1999. Genetic diversity and biocontrol activity of Aureobasidium pullulans isolates against postharvest rots. Postharvest Biol. Technol. 17, 189-199.

Schulz, B., Boyle, C., Draegher, S., Römmert, A.K., Krohn, K., 2002. Endophytic fungi: a source of novel biologically active secondary metabolites. Mycol. Res. 9, 996-1004.

Simmons, E.G., 1992. Alternaria taxonomy: current status, viewpoint, challenge. In: Chelkowski, J., Visconti, A. (Eds.), Alternaria Biology, Plant Disease and Metabolites. Elsevier, Amsterdam, The Netherlands, pp. 1-35.

Simmons, E.G., Roberts, R.G., 1993. Alternaria themes and variations. Mycotaxon 48, 109-140.

Su, Y.-Y., Guo, L.-D., Hyde, K.D., 2010. Response of endophytic fungi of Stipa grandis to experimental plant function group removal in Inner Mongolia steppe. China. Fund. Div. 43, 93-101

Tan, R.X., Zou, W.X., 2001. Endophytes: a rich source of functional metabolites. Nat. Prod. 18, 448-459.

Wold, S., Sjöström, M., Eriksson, L., 2001. PLS-regression: a basic tool of chemometrics. Chemom. Intell. Lab. Sys. 58, 109-130. 